\title{
A potential nitrergic mechanism of action for indomethacin, but not of other COX inhibitors: relevance to indomethacin-sensitive headaches
}

\author{
Oliver Summ • Anna P. Andreou - Simon Akerman • \\ Peter J. Goadsby
}

Received: 17 August 2010/Accepted: 1 September 2010/Published online: 27 October 2010

(C) The Author(s) 2010. This article is published with open access at Springerlink.com

\begin{abstract}
Non-steroidal anti-inflammatory drugs (NSAIDs) that act as cyclo-oxygenase (COX) inhibitors are commonly used in the treatment of a range of headache disorders, although their mechanism of action is unclear. Indomethacin is of particular interest given its very special effect in some primary headaches. Here the in vivo technique of intravital microscopy in rats has been utilised as a model of trigeminovascular nociception to study the potential mechanism of action of indomethacin. Dural vascular changes were produced using electrical (neurogenic) dural vasodilation (NDV), calcitonin gene-related peptide (CGRP) induced dural vasodilation and nitric oxide (NO) induced dural vasodilation using NO donors. In each of these settings the effect of intravenously administered indomethacin $\left(5 \mathrm{mg} \mathrm{kg}^{-1}\right)$, naproxen $\left(30 \mathrm{mg} \mathrm{kg}^{-1}\right)$ and ibuprofen $\left(30 \mathrm{mg} \mathrm{kg}^{-1}\right)$ was tested. All of the tested drugs significantly inhibited NDV (between 30 and 52\%). Whilst none of them was able to inhibit CGRP-induced dural vasodilation, only indomethacin reduced $\mathrm{NO}$ induced dural vasodilation ( $35 \pm 7 \%, 10$ min post administration). We conclude NSAIDs inhibit release of CGRP after NDV without an effect on CGRP directly. Further we describe a differentiating effect of indomethacin inhibiting nitric oxide induced dural vasodilation that is potentially relevant to understanding its unique action in disorders such as paroxysmal hemicrania and hemicrania continua.
\end{abstract}

Enrico Greppi Selection Committee 2010: Vincenzo Guidetti, Fabio Antonaci, Paolo Martelletti, Michael A. Moskowitz, Rigmor Jensen, Francesco Pierelli.

O. Summ · A. P. Andreou · S. Akerman · P. J. Goadsby $(\square)$

Headache Group, Department of Neurology,

University of California, 1701 Divisadero St,

Suite 480, San Francisco, CA 94115, USA

e-mail: pgoadsby@headache.ucsf.edu
Keywords Trigeminal $\cdot$ NSAID $\cdot$ COX $\cdot$ Headache $\cdot$ Vasodilation · Rat

\section{Introduction}

Non-steroidal anti-inflammatory drugs (NSAIDs) are probably among the most widely used analgesics used to treat headache, including many of the primary headache disorders. For migraine, where they are the first line treatment for acute attacks, they offer the most cost effective treatment showing only minor side effects [1]. Although these substances have been used clinically for many years, and it is known that they share mechanisms that involve inhibition of the different cyclooxygenases (COX) [2,3], it is not clear which mechanisms, apart from the known COX-1/-2 inhibition, defines their different clinical profiles relevant for the treatment of headaches. The role of some NSAIDs has been investigated previously in animal models of migraine pathways and have demonstrated an inhibitory effect on neuronal firing in the TCC after dural stimulation $[4,5]$ and naproxen has been shown capable of inhibiting central sensitization [6], a phenomenon often thought to contribute, at the very least, to the cutaneous allodynia observed in migraine patients. Among the NSAIDs indomethacin stands out for its particular effect on a range of primary headache disorders that are regarded as indomethacin-sensitive, notably paroxysmal hemicrania and hemicrania continua [7], although the basis for is special effect is unknown.

Indomethacin has been shown to be effective in the model of trigeminovascular nociception using intravital microscopy of the dural vasculature [8]. Also, by testing the effect of various intracisternally administered COX inhibitors, including indomethacin, on trigeminal ganglion 
compression the resulting allodynic response was inhibited [9], highlighting the likelihood of COX being a potential target within the CNS for the treatment of headache. Like other NSAIDs indomethacin inhibits COX-1/-2 and in this aspect differs from others in the ratio of that effect [10-12]. However, these differences in COX effects are not so marked, such that additional mechanisms have been discussed and the exact mechanism of action relevant to indomethacin-sensitive headaches remains unclear.

Intravital microscopy as a model for trigeminovascular nociception monitors dural vessel diameter in response to external stimuli, chemical or electrical, and relates the dilatory response to trigeminovascular activation. Utilizing this well established technique $[13,14]$ it has been shown that indomethacin causes vasoconstriction of nitric oxideinduced vasodilation [8]. However, no direct comparison with other NSAIDs has been made within the same experimental setup that uses dural vessels as a model of trigeminovascular activation. Here we aimed to measure and compare effects of indomethacin, naproxen and ibuprofen on vasodilation of the middle meningeal artery, induced by electrical stimulation of the dura mater, as well as chemical stimulation by intra arterial application of the known vasodilators CGRP and sodium nitroprusside, a nitric oxide donor. Both CGRP [15] and NO donors [16] have been demonstrated to cause vasodilation of intracranial blood vessels and an immediate headache in all patients, but also cause a delayed migraine in migraineurs. They therefore provide important translational approaches for understanding the mechanism of action of therapeutics. Separating unique mechanisms of action of indomethacin is crucial in developing new treatments independent from COX-1/-2 inhibition, which may have less gastrointestinal side effects yet still benefit patients with "indomethacinsensitive" headaches.

\section{Methods}

\section{General procedures}

All experiments were conducted under license of the University of California, San Francisco Institutional Animal Care and Use Committee and conforming to the National Institutes of Health Guide for the Care and Use of Laboratory Animals.

For experiments male Sprague-Dawley rats (280-390 g) were anesthetized with sodium pentobarbital $\left(60 \mathrm{mg} \mathrm{kg}^{-1}\right.$; i.p.). The left femoral artery and veins of both sides were cannulated for blood pressure monitoring (CT-1000+ ALM 932, CWE Inc., Ardmore, PA, USA) and further administration of anesthetics (pentobarbital $25-30 \mathrm{mg} \mathrm{kg}^{-1} \mathrm{~h}^{-1}$ ) and drug administration, respectively. The animals were ventilated with oxygen enriched air, 2-3 ml, 80-100 strokes $\min ^{-1}$ (Small rodent ventilator-Model 683, Harvard Instruments, Kent, U.K.) after cannulation with a tracheal tube. End Tidal $\mathrm{CO}_{2}$ was monitored (Capstar-100, CWE Inc., Ardmore, PA, USA) and kept between 3.5 and $4.5 \%$. A thermostatically controlled homeothermic blanket system was used to keep the body temperature in physiological range. The blood pressure (BP), end tidal $\mathrm{CO}_{2}$, and temperature were electronically displayed. Animals were fixed in a stereotactic frame for the surgery and recordings. The withdrawal reflex after paw pinch and testing of the corneal reflexes were recorded allowing monitoring of the depth of anesthesia.

Data for all experiments were displayed and saved on a personal computer using an online data analysis system (Power 1401plus, CED and Spike5 software, UK).

At the end of the experiments animals were euthanized by a lethal dose of pentobarbital.

\section{Intravital microscopy}

The carotid artery was cannulated for all experiments and used to administer the chemical dilators, CGRP and the NO donor sodium nitroprusside (SNP). It has been demonstrated previously that using the intracarotid route of administration reduces significantly the overall concentration of molecules required to induce maximal dural blood vessel dilation, while minimizing cardiovascular effects compared to the more commonly used intravenous route [14].

After exposing the skull, the parietal bone of the right or left side was thinned using a saline cooled dental drill until the underlying vessels of the dura mater were clearly visible and the skull was left intact (closed window). The area was then covered with mineral oil $\left(37^{\circ} \mathrm{C}\right)$ and a branch of the middle meningeal artery (MMA) was then focused on and projected onto a TV monitor using an intravital microscope (Microvision MV2100, UK). On-line monitoring of the blood vessel diameter was achieved through a video dimension analyzer (Living System Instrumentation, USA) [17]. After a resting period and evaluation of a steady vessel diameter, one of the following protocols was applied.

\section{Neurogenic dural vasodilation (NDV)}

A bipolar stimulation electrode (NE 200, Clark Electromedical) was placed within a range of about $200 \mu \mathrm{m}$ to the monitored vessel. The bone adjacent to the MMA was stimulated with constant settings for stimulation adjusted to $5 \mathrm{~Hz} 1 \mathrm{~ms}$ for $10 \mathrm{~s}$ (Grass Stimulator S88, Grass Instrumentation, USA). For each animal the voltage was increased until a maximal dilation was observed, the resulting current was monitored on an oscilloscope ranging between 100 and $160 \mu \mathrm{A}$. All following stimulations were then performed using this voltage $[18,19]$. 


\section{Calcitonin gene-related peptide (CGRP)-induced dilation}

CGRP $\left(1 \mu \mathrm{g} \mathrm{kg}^{-1}\right.$ dissolved in $\left.0.9 \% \mathrm{NaCl}\right)$ was given i.a. over $3 \mathrm{~min}$ and demonstrated the maximal dilatory effect. Following a recovery period of $17 \mathrm{~min}$, the infusion of CGRP was then repeated. By following this time pattern it was possible to ensure a sufficient recovery as well as to evaluate vasodilatory responses at the same time points as with nitric oxide induced dilation. The two vascular responses were recorded and summarized as the baseline response. After recovery from the second infusion of CGRP the control or one of the COX inhibitors was injected i.v. The pattern of CGRP-injection followed by a $17 \mathrm{~min}$ recovery period was then repeated for four times starting $10 \mathrm{~min}$ after the injection of the vehicle or drug.

\section{Nitric oxide induced dilation}

SNP $\left(2 \mu \mathrm{g} \mathrm{kg}^{-1} \mathrm{~min}^{-1}\right.$ dissolved in $\left.0.9 \% \mathrm{NaCl}\right)$ was given i.a. over $5 \mathrm{~min}$ as similar doses have shown a maximal dilatory effect [8]. This was followed by a recovery period of $15 \mathrm{~min}$, the injection of SNP was then repeated. The two vascular responses were recorded and summarized as the baseline response. $15 \mathrm{~min}$ after the second baseline either control or one of the drugs was injected i.v. The injection of the NO donor SNP followed by a $15 \mathrm{~min}$ recovery period was repeated $10 \mathrm{~min}$ after the injection of the drug for four times. Each animal only received a single dose of a NSAID.

\section{Drugs}

For intravenous application indomethacin was dissolved in $0.9 \% \mathrm{NaCl}$ solution $\left(5 \mathrm{mg} \mathrm{ml}^{-1}\right)$ and administered at the dose of $5 \mathrm{mg} \mathrm{kg}^{-1}$. Naproxen and Ibuprofen were dissolved in $0.9 \% \mathrm{NaCl}\left(30 \mathrm{mg} \mathrm{ml}^{-1}\right)$ and the dose for administration was $30 \mathrm{mg} \mathrm{kg}^{-1}$. An equal volume of saline was used in the control group. All solutions were $\mathrm{pH}$ adjusted to $\mathrm{pH} 8-8.3$.

\section{Statistics}

Statistical analysis was carried out using SPSS (18.0, IL, USA). For repeated measures an analysis of variance (ANOVA) was performed. In case the assumption of sphericity was violated Greenhouse-Geisser corrections were applied. Bonferroni correction was applied for multiple comparisons if applicable. Statistical significance was set at $P<0.05$. In case of $P$ values $<0.05$ post-hoc comparisons were made using independent $t$ tests for group comparisons of the different interventions. All results are expressed as percentages of baseline responses.

\section{Results}

General

A total of 63 animals were used for these experiments. The monitored vessel diameters at rest ranged between 40 and $150 \mu \mathrm{m}$. The slow intravenous administration of indomethacin, naproxen and ibuprofen caused a slight and transient blood pressure increase accompanied by a light constriction of the monitored vessel. However vessel diameter recovered back to baseline readings before any induced dilation similar to previous reports for indomethacin [8].

Vehicle control had no effect on the baseline values of $\mathrm{BP}$ or vessel diameter.

\section{Neurogenic dural vasodilation (NDV)}

NDV was used to examine the effect of all test substances in 23 animals. Stimulation dilated the dural vessels by $239 \pm 14 \%$ of their resting diameter. Whilst the baseline responses of the control and drug groups were stable and administration of vehicle control $(N=5)$ did not alter the vascular responses $\left(F_{4,16}=0.562, P>0.05\right)$, all tested drugs attenuated NDV.

Indomethacin $(N=6)$ significantly inhibited NDV $\left(F_{4,20}=3.043, P<0.05\right)$ by $29 \pm 5 \%$ at $10 \mathrm{~min}\left(t_{9}=\right.$ $5.349, P<0.001)$, by $20 \pm 8 \%$ at $25 \mathrm{~min}\left(t_{9}=2.683\right.$, $P<0.05)$ and by $30 \pm 12 \%$ at $40 \mathrm{~min}\left(t_{9}=2.586\right.$, $P<0.05)$ when compared to control. Naproxen $(N=6)$ inhibited NDV $\left(F_{4,20}=6.978, P \leq 0.001\right)$ by $44 \pm 10 \%$ at $10 \min \left(t_{9}=4.383, P<0.05\right)$, by $34 \pm 12 \%$ at $25 \mathrm{~min}$ $\left(t_{9}=2.776, P<0.05\right)$, by $52 \pm 13 \%$ at $40 \mathrm{~min}\left(t_{9}=\right.$ $3.993, P<0.05)$ and by $35 \pm 14 \%$ at $55 \min \left(t_{9}=2.550\right.$, $P<0.05)$ when compared to control. Ibuprofen $(N=6)$ significantly attenuated NDV $\left(F_{4,20}=6.654, P \leq 0.001\right)$ by $26 \pm 10 \%$ at $25 \mathrm{~min}\left(t_{9}=2.562, P<0.05\right)$, by $30 \pm 12 \%$ at $40 \mathrm{~min}\left(t_{9}=2.440, \quad P<0.05\right)$ and by $28 \pm 9 \%$ at $55 \mathrm{~min}\left(t_{9}=3.007, P<0.05\right)$ when compared to control (Fig. 1).

\section{Calcitonin gene-related peptide induced dilation}

A total of 20 animals were used for monitoring the effects of the tested drugs on CGRP induced dilation. Infusion of CGRP induced an increase of the vessel diameter to $191 \pm 5 \%$ of the resting state. CGRP infusion also caused a transient drop of blood pressure within physiological range, not exceeding $3 \mathrm{~min}$ post infusion. Intravenous administration of vehicle control $(N=5)$, indomethacin $(N=5)$, naproxen $(N=5)$ and ibuprofen $(N=5)$ had no effect on the NO-induced vessel dilation $(P \geq 0.21)$ (Fig. 2). The blood pressure was reduced to $78 \pm 2 \%$ of 


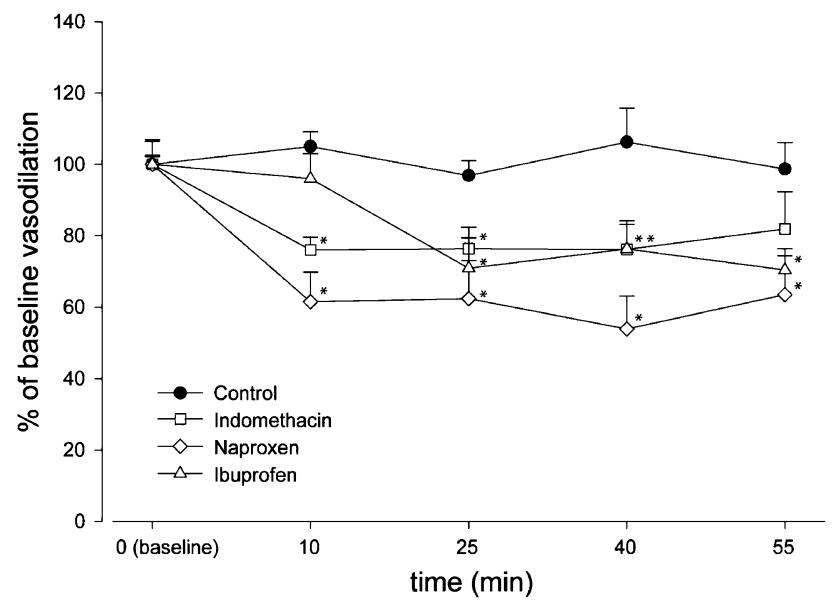

Fig. 1 Effect of COX inhibitors on electrical stimulation induced vasodilation of the middle meningeal artery in intravital microscopy. After the baseline response was established one of the drugs (indomethacin $5 \mathrm{mg} \mathrm{kg}^{-1}$, naproxen $30 \mathrm{mg} \mathrm{kg}^{-1}$ or ibuprofen 30 $\mathrm{mg} \mathrm{kg}^{-1}$ ) was applied intravenously, followed by four further electrical stimulations with a $15 \mathrm{~min}$ recovery period, starting $10 \mathrm{~min}$ after the administration of one of the drugs. Each of the administered drugs was able to significantly attenuate neurogenic vasodilation. $* P<0.05$

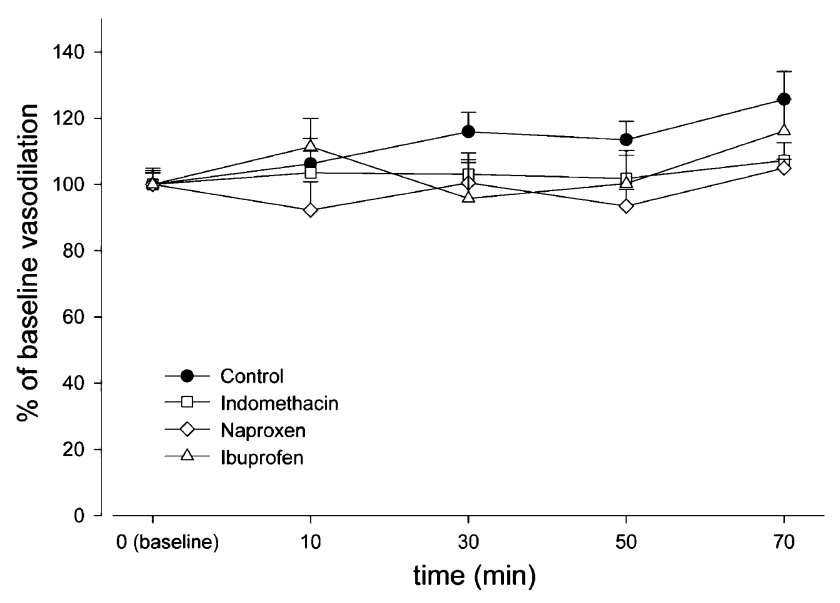

Fig. 2 Effect of COX inhibitors on repeated CGRP $\left(0.33 \mu \mathrm{g} \mathrm{kg}^{-1} \mathrm{~min}^{-1}\right.$ over $3 \mathrm{~min}$ intra-arterial) induced vasodilations in intravital microscopy. After the baseline response was established one of the drugs (indomethacin $5 \mathrm{mg} \mathrm{kg}^{-1}$, naproxen $30 \mathrm{mg} \mathrm{kg}^{-1}$ or ibuprofen $30 \mathrm{mg} \mathrm{kg}^{-1}$ ) was applied intravenously, followed by four further CGRP infusions with a $17 \mathrm{~min}$ recovery period, starting 10 min after the administration of one of the drugs. None of the drugs altered the vessel response to CGRP infusion

the level at rest by infusion of CGRP. The reduction was short lasting with an immediate recovery to baseline reading within 3-5 min. The administration of vehicle control or any of the drugs used did not alter this response.

\section{Nitric oxide induced dilation}

The effect of the selected compounds was tested on NO induced dilation in 20 animals by intra-arterial administration of SNP. Infusion of SNP induced an increase of the vessel diameter to $185 \pm 7 \%$ of the resting state, accompanied by a minor and transient drop in blood pressure, which recovered to baseline readings within 3 min of the end of the infusion. Administration of control $(N=5)$, naproxen $(N=5)$ and ibuprofen $(N=5)$ had no effect on the NO-induced vessel dilation $(P \geq 0.17)$. However, indomethacin $(N=5)$ did inhibit the vasodilation $\left(F_{4,16}=5.143, P<0.05\right)$ at $10 \mathrm{~min}$ by $35 \pm 7 \%$ $\left(t_{8}=4.773, \quad P \leq 0.001\right), \quad 30 \mathrm{~min}$ by $33 \pm 12 \% \quad\left(t_{8}=\right.$ $2.729, \quad P<0.05) \quad 50 \mathrm{~min}$ by $31 \pm 13 \% \quad\left(t_{8}=2.425\right.$, $P<0.05) \quad$ and $70 \mathrm{~min}$ by $34 \pm 14 \% \quad\left(t_{8}=2.324\right.$, $P<0.05$ ) when compared to control (Fig. 3a). Infusion of the SNP induced a decrease of the blood pressure to $71 \pm 2 \%$ of readings at rest. The BP decrease was short lasting with a full recovery to baseline readings within 3-5 min. Whilst vehicle control, naproxen and ibuprofen left the BP response unaltered $(P \geq 0.13)$, indomethacin decreased the percentage of BP reduction induced by SNP infusion $\left(F_{4,16}=3.218, P<0.05\right)$. When compared to control indomethacin reduced the BP response to SNP infusion by $23 \pm 10 \%\left(t_{8}=2.729, P<0.05\right) 10 \mathrm{~min}$ after administration, $30 \pm 8 \%\left(t_{8}=2.342, P<0.05\right) 30 \mathrm{~min}$ after administration, $31 \pm 3 \% \quad\left(t_{8}=9.757, \quad P<0.001\right)$ $50 \mathrm{~min}$ after administration and $37 \pm 13 \%\left(t_{8}=2.942\right.$, $P<0.05$; Fig. 3b).

\section{Discussion}

The data demonstrate indomethacin, naproxen and ibuprofen are able to inhibit dural vasodilation induced by electrical stimulation, with ibuprofen showing a later onset of the inhibition, and indomethacin a shorter duration of the effect when compared to the two other drugs used. There was no inhibition of CGRP infusion induced dural vasodilation with any of the tested drugs. The most interesting finding is that indomethacin was able to inhibit NO induced vasodilation as well reducing the hypotensive effect of the SNP infusion, whereas naproxen and ibuprofen had no effect. This clearly separates indomethacin from the other NSAIDs tested and suggests that indomethacin can inhibit mechanisms related NO. Understanding the NO inhibiting effect of indomethacin in concert with the COX1/2 effects may hold an important key for the development of new approaches to the management of indomethacin-sensitive headaches.

Drug doses in our study were based on the $\mathrm{LD}_{10}$ of indomethacin after oral dosage of indomethacin in rat being slightly higher than the dose used [20]. The doses of naproxen and ibuprofen were adjusted according to the clinically recommended maximum daily dose for headache treatment in humans, e.g. $200 \mathrm{mg} \mathrm{day}^{-1}$ indomethacin, 

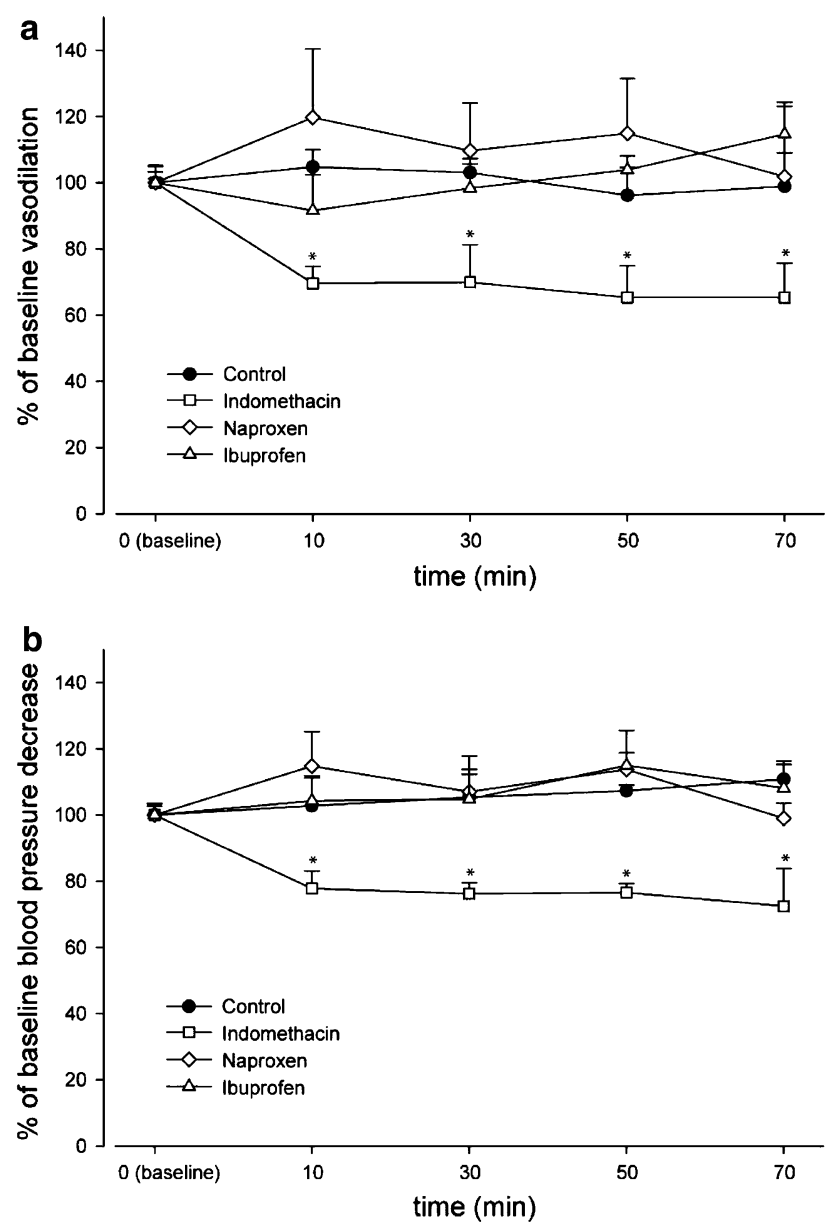

Fig. 3 Effect of COX inhibitors on dural vasodilation, induced by repeated sodium nitroprusside infusions, $2 \mu \mathrm{g} \mathrm{kg}^{-1} \mathrm{~min}^{-1}$ over $5 \mathrm{~min}$ intra arterial, in intravital microscopy (a) and on the blood pressure decrease caused by the repeated infusion of sodium nitroprusside prior and post drug or control administration (b). After the baseline response was established one of the drugs (indomethacin $5 \mathrm{mg} \mathrm{kg}^{-1}$, naproxen $30 \mathrm{mg} \mathrm{kg}^{-1}$ or ibuprofen $30 \mathrm{mg} \mathrm{kg}^{-1}$ ) was applied intravenously, followed by four further sodium nitroprusside infusions with a 15 min recovery period, starting $10 \mathrm{~min}$ after the administration of one of the drugs. Of all drugs used only indomethacin shows an inhibitory effect on nitric oxide induced vasodilation as well as on the blood pressure decrease induced by the infusion of sodium nitroprusside. ${ }^{*} P<0.05$

$1200 \mathrm{mg} \mathrm{day}^{-1}$ naproxen or $1200 \mathrm{mg} \mathrm{day}^{-1}$ ibuprofen (ratio: 1:6:6). As all of these drugs are about $98 \%$ absorbed in humans, we used the doses that reflect the ratio used in clinical practice. However, the inhibition of dural vasodilation shown for indomethacin reflects somewhat previous results [8] with effect sizes between the ones demonstrated for the doses of 3 and $10 \mathrm{mg} \mathrm{kg}^{-1}$ used in the reported experiments, with similar doses having been used successfully in previous work [21, 22].

Neurogenic vasodilation is believed to act via neuronal release of CGRP from trigeminovascular neurons, meaning that the effect seen with this technique must be due to an interaction of the successfully used drugs with either the release of CGRP from the trigeminovascular neurons, the drug with the CGRP or the CGRP receptor itself, or with both [18, 23]. CGRP acts as a vasodilator via an induction of adenylate cyclase within the vascular smooth muscle cells [24]. The observation that none of the tested drugs inhibited CGRP induced vasodilation suggests the effect of these drugs is most likely via pre-synaptic inhibition of CGRP release from trigeminovascular neurons.

NO induced vasodilation can occur via an activation of guanylate cyclase, which in turn raises the cyclic guanosine monophosphate (cGMP) synthesis. Relaxation of the smooth muscle cell and thereby vasodilation is finally caused by the decrease of $\mathrm{Ca}^{2+}$ [25]. However, additional mechanisms that include a coupling of NO and CGRP release have been discussed [8, 18, 26, 27]. Great interest lies on the involvement of NO induced mechanisms within the trigeminal pathway since it is known that NO can induce headache with the clinical phenotype of migraine [28, 29]. This migraine-like headache is delayed and develops after a more immediate onset headache with glyceryltrinitrate (GTN) administration. Not limited to migraine, it also is known that GTN can trigger attacks in cluster headache patients during an active headache episode [30] and it has been reported that GTN can trigger paroxysmal hemicrania [31]. Migraine after GTN develops several hours after administration, while cluster headache takes tens of minutes, suggesting direct vasodilation is the cause of the pain. Indeed vasodilation is not present in migraine when the attack starts [32]. The suggested mechanisms for the development of these headaches are therefore believed to be transmitted by second messengers. In turn the case report of the GTN induced paroxysmal headache demonstrates an early onset. The observation that indomethacin was able to inhibit NO induced vasodilation might therefore be important in understanding its effect in paroxysmal hemicrania or hemicrania continua, indeed acting as a marker for the effect. Unfortunately our understanding of the underlying mechanisms of NOinduced headache is still very limited.

Indomethacin does inhibit NO production from rat microglia [33]. Indeed NO generation is involved in the cranial parasympathic loop [34] that is active in trigeminal autonomic cephalalgias (TACs) [35]. In a study monitoring the meningeal blood flow during local application of vasodilators as well as potential antagonists it was concluded that NO dependent blood flow release is independent of the release of prostaglandins, a product of cyclooxygenases, but is co-induced by a NO triggered CGRP release [27]. The model used did not reflect trigeminal activation itself, and only local effects were monitored. It is not known if the mechanism accompanying the vasodilatory effect is the cause of the induced 
paroxysmal hemicrania, as NO is highly capable of crossing the blood brain barrier and local effects within certain areas of the CNS are highly probable. It is very important to note that the vasodilatory effect of NO itself is not likely to be the pain inducing mechanism, it is in fact more likely that other mechanisms induced by NO, that are accompanied by the vasodilatory effect, are causing the early onset headache.

Painful stimuli within the trigeminovascular system can, themselves, cause vasodilation, while pain is not necessarily caused by vasodilation [35]. It has been documented in in vitro experiments that elevated NO levels are capable of increasing COX-1 activity within trigeminal satellite cells [36], demonstrating a non-vascular mechanism of NO within the migraine pathway. In earlier experiments it was also shown that COX-2 inhibition but not COX-1 inhibition can decrease the level of neuronal nitric oxide synthase induction as induced by NO donors [37]. The substances used in our experiment all show activity on COX-1 and -2 with different pharmacologically kinetics. Indomethacin shows time dependent tight binding, naproxen shows time dependent weak binding and ibuprofen acts via competitive inhibition on COX-1/-2 [10].

Indomethacin, as well as other NSAIDs, shows a good penetrability of the blood brain barrier and therefore can target mechanisms within the CNS [38, 39]. Naproxen showed the lowest concentrations within the brain in comparison to the plasma levels but did reach effective doses [38]. In the study of Parepally et al. [39] only ibuprofen had a saturable transport, which may explain its delayed effect on NDV compared to indomethacin and naproxen. A mechanism where no direct correlation to the COX inhibitory effect of the NSAIDs can be seen was uncovered after the observation has been made that long term medication with NSAIDs can lower the risk for development Alzheimer's disease [40]. Eriksen et al. [38] were able to show that indomethacin and ibuprofen were able to decrease significantly formation of the amyloid $\beta 42$ amino acid form of amyloid beta, whilst naproxen had no significant effect. Taken together it is plausible that the site of action of indomethacin in headache may be within the central nervous system.

In conclusion, each of the NSAIDs tested, indomethacin, ibuprofen and naproxen, have clear effects on neurogenic dural vasodilation (NDV) in line with their efficacy in migraine. Moreover, there was no effect of these compounds on CGRP-induced vasodilation suggesting that the NDV effect is prejunctional. Only indomethacin inhibits NO-induced dural vasodilation. It is plausible that the NO effect is the crucial added mechanism that allows indomethacin to be so effective in conditions such as paroxysmal hemicrania and hemicrania continua. These offer the prospect of developing medicines targeting NO mechanisms that may then provide novel approaches to the treatment of indomethacin-sensitive headaches.

\section{Conflict of interest None.}

Open Access This article is distributed under the terms of the Creative Commons Attribution Noncommercial License which permits any noncommercial use, distribution, and reproduction in any medium, provided the original author(s) and source are credited.

\section{References}

1. Goadsby PJ, Lipton RB, Ferrari MD (2002) Migraine-current understanding and treatment. N Engl J Med 346:257-270

2. Smith WL, Meade EA, DeWitt DL (1994) Pharmacology of prostaglandin endoperoxide synthase isozymes-1 and -2. Ann N Y Acad Sci 714:136-142

3. Wallace JL (1999) Distribution and expression of cyclooxygenase (COX) isoenzymes, their physiological roles, and the categorization of nonsteroidal anti-inflammatory drugs (NSAIDs). Am J Med 107:11S-16S

4. Kaube H, Hoskin KL, Goadsby PJ (1993) Intravenous acetylsalicylic acid inhibits central trigeminal neurons in the dorsal horn of the upper cervical spinal cord in the cat. Headache 33:541-550

5. Ellrich J, Schepelmann K, Pawlak M, Messlinger K (1999) Acetylsalicylic acid inhibits meningeal nociception in rat. Pain 81:7-14

6. Jakubowski M, Levy D, Kainz V, Zhang XC, Kosaras B, Burstein $R$ (2007) Sensitization of central trigeminovascular neurons: blockade by intravenous naproxen infusion. Neuroscience 148:573-583

7. Headache Classification Committee of The International Headache Society (2004) The International Classification of Headache Disorders (second edition). Cephalalgia 24(Suppl 1): $1-160$

8. Akerman S, Kaube H, Goadsby PJ (2002) The effect of antimigraine compounds on nitric oxide induced dilation of dural meningeal vessels. Eur J Pharmacol 452:223-228

9. Yang GY, Lee MK, Bae YC, Ahn DK (2009) Intracisternal administration of COX inhibitors attenuates mechanical allodynia following compression of the trigeminal ganglion in rats. Prog Neuropsychopharmacol Biol Psychiatry 33:589-595

10. Gierse JK, Koboldt CM, Walker MC, Seibert K, Isakson PC (1999) Kinetic basis for selective inhibition of cyclo-oxygenases. Biochem J 339(Pt 3):607-614

11. Mitchell JA, Akarasereenont P, Thiemermann C, Flower RJ, Vane JR (1993) Selectivity of nonsteroidal antiinflammatory drugs as inhibitors of constitutive and inducible cyclooxygenase. Proc Natl Acad Sci USA 90:11693-11697

12. Noreen Y, Ringbom T, Perera P, Danielson H, Bohlin L (1998) Development of a radiochemical cyclooxygenase- 1 and -2 in vitro assay for identification of natural products as inhibitors of prostaglandin biosynthesis. J Nat Prod 61:2-7

13. Andreou AP, Summ O, Charbit AR, Romero Reyes M, Goadsby PJ (2010) Animal models of headache-from bedside to bench and back to beside. Exp Rev Neurother 10:389-411

14. Gupta S, Bhatt DK, Boni LJ, Olesen J (2010) Improvement of the closed cranial window model in rats by intracarotid infusion of signalling molecules implicated in migraine. Cephalalgia

15. Lassen LH, Jacobsen VB, Haderslev PA, Sperling B, Iversen HK, Olesen $\mathrm{J}$ et al (2008) Involvement of calcitonin gene-related 
peptide in migraine: regional cerebral blood flow and blood flow velocity in migraine patients. J Headache Pain 9:151157

16. Iversen HK, Olesen J (1994) Nitroglycerin-induced headache is not dependent on histamine release: support for a direct nociceptive action of nitric oxide. Cephalalgia 14:437-442

17. Akerman S, Goadsby PJ (2005) The role of dopamine in a model of trigeminovascular nociception. J Pharmacol Exp Ther 314: 162-169

18. Akerman S, Williamson DJ, Kaube H, Goadsby PJ (2002) Nitric oxide synthase inhibitors can antagonise neurogenic and calcitonin gene-related peptide induced dilation of dural meningeal vessels. Br J Pharmacol 137:62-68

19. Williamson DJ, Hargreaves RJ, Hill RG, Shepheard SL (1997) Sumatriptan inhibits neurogenic vasodilation of dural blood vessels in the anaesthetized rat- intravital microscope studies. Cephalalgia 17:525-531

20. Omogbai EK, Ozolua RI, Idaewor PE, Isah AO (1999) Some studies on the rodenticidal action of indomethacin. Drug Chem Toxicol 22:629-642

21. Wagerle LC, Degiulio PA (1994) Indomethacin-sensitive $\mathrm{CO}_{2}$ reactivity of cerebral arterioles is restored by vasodilator prostaglandin. Am J Physiol 266:H1332-H1338

22. Busija DW, Leffler CW, Wagerle LC (1990) Mono-L-Arginine containing compounds dilate piglet pial arterioles via an endothelium-derived relaxing factor like substance. Circ Res 67:1374-1380

23. Akerman S, Kaube H, Goadsby PJ (2002) Vanilloid receptor 1 (VR1) evoked CGRP release plays a minor role in causing dural vessel dilation via the trigeminovascular system. Cephalalgia 22:572

24. Edwards RM, Stack EJ, Trizna W (1991) Calcitonin gene-related peptide stimulates adenylate cyclase and relaxes intracerebral arterioles. J Pharmacol Exp Ther 257:1020-1024

25. Moncada S, Palmer RMJ, Higgs EA (1991) Nitric oxide: physiology, pathophysiology, and pharmacology. Pharmacol Rev 43:109-142

26. Messlinger K, Suzuki A, Pawlak M, Zehnter A, Schmidt RF (2000) Involvement of nitric oxide in the modulation of dural arterial blood flow in the rat. Br J Pharmacol 129:1397-1404

27. Strecker T, Dux M, Messlinger K (2002) Increase in meningeal blood flow by nitric oxide-interaction with calcitonin gene- related peptide receptor and prostaglandin synthesis inhibition. Cephalalgia 22:233-241

28. Iversen H (2001) Human migraine models. Cephalalgia 21:781-785

29. Sances G, Tassorelli C, Pucci E, Ghiotto N, Sandrini G, Nappi G (2004) Reliability of the nitroglycerin provocative test in the diagnosis of neurovascular headaches. Cephalalgia 24:110-119

30. Ekbom K (1968) Nitroglycerin as a provocative agent in cluster headache. Arch Neurol 19:487-493

31. Giffin NJ (2007) Paroxysmal hemicrania triggered by GTN Cephalalgia 27:953-954

32. Schoonman GG, van der Grond J, Kortmann C, van der Geest RJ, Terwindt GM, Ferrari MD (2008) Migraine headache is not associated with cerebral or meningeal vasodilatation-a $3 \mathrm{~T}$ magnetic resonance angiography study. Brain 131:2192-2200

33. Du ZY, Li XY (1999) Inhibitory effects of indomethacin on interleukin-1 and nitric oxide production in rat microglia in vitro. Int $\mathbf{J}$ Immunopharmacol 21:219-225

34. Goadsby PJ, Uddman R, Edvinsson L (1996) Cerebral vasodilatation in the cat involves nitric oxide from parasympathetic nerves. Brain Res 707:110-118

35. May A, Goadsby PJ (1999) The trigeminovascular system in humans: pathophysiological implications for primary headache syndromes of the neural influences on the cerebral circulation. J Cereb Blood Flow Metab 19:115-127

36. Capuano A, De Corato A, Lisi L, Tringali G, Navarra P, Dello Russo C (2009) Proinflammatory-activated trigeminal satellite cells promote neuronal sensitization: relevance for migraine pathology. Mol Pain 5:43

37. Varga H, Pardutz A, Vamos E, Plangar I, Egyud E, Tajti J et al (2007) Cox-2 inhibitor attenuates NO-induced nNOS in rat caudal trigeminal nucleus. Headache 47:1319-1325

38. Eriksen JL, Sagi SA, Smith TE, Weggen S, Das P, McLendon DC et al (2003) NSAIDs and enantiomers of flurbiprofen target gamma-secretase and lower Abeta 42 in vivo. J Clin Invest 112:440-449

39. Parepally JM, Mandula H, Smith QR (2006) Brain uptake of nonsteroidal anti-inflammatory drugs: ibuprofen, flurbiprofen, and indomethacin. Pharm Res 23:873-881

40. Weggen S, Eriksen JL, Das P, Sagi SA, Wang R, Pietrzik CU et al (2001) A subset of NSAIDs lower amyloidogenic Abeta42 independently of cyclooxygenase activity. Nature 414:212-216 